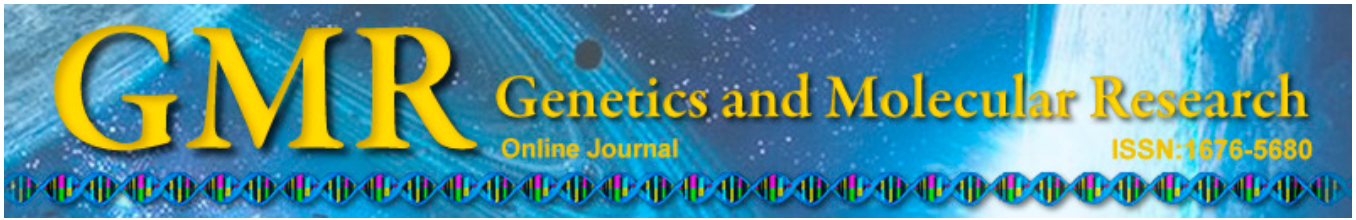

\title{
Construction of an integrated genetic map for Capsicum baccatum $\mathrm{L}$.
}

\author{
M.M. Moulin 1 , R. Rodrigues 2 , H.C.C. Ramos ${ }^{2}$, C.S. Bento ${ }^{2}$, C.P. Sudré , \\ L.S.A. Gonçalves ${ }^{3}$ and A.P. Viana ${ }^{2}$ \\ ${ }^{1}$ Laboratório de Genética e Biologia Molecular, \\ Instituto Federal do Espírito Santo, Alegre, ES, Brasil \\ ${ }^{2}$ Laboratório de Melhoramento Genético Vegetal, \\ Universidade Estadual do Norte Fluminense Darcy Ribeiro, \\ Campos dos Goytacazes, RJ, Brasil \\ ${ }^{3}$ Laboratório de Melhoramento Genético Vegetal, \\ Universidade Estadual de Londrina, Londrina, PR, Brasil \\ Corresponding author: M.M. Moulin \\ E-mail:mmmoulin@ifes.edu.br
}

Genet. Mol. Res. 14 (2): 6683-6694 (2015)

Received July 28, 2014

Accepted January 23, 2015

Published June 18, 2015

DOI http://dx.doi.org/10.4238/2015.June.18.12

\begin{abstract}
Capsicum baccatum L. is one of the five Capsicum domesticated species and has multiple uses in the food, pharmaceutical and cosmetic industries. This species is also a valuable source of genes for chili pepper breeding, especially genes for disease resistance and fruit quality. However, knowledge of the genetic structure of $C$. baccatum is limited. A reference map for C. baccatum $(2 \mathrm{n}=2 \mathrm{x}=24)$ based on 42 microsatellite, 85 inter-simple sequence repeat, and 56 random amplified polymorphic DNA markers was constructed using an $\mathrm{F}_{2}$ population consisting of 203 individuals. The map was generated using the JoinMap software (version 4.0) and the linkage groups were formed and ordered using a LOD score of 3.0 and maximum of $40 \%$ recombination. The genetic map consisted of 12 major and four minor linkage groups covering a total genome distance of $2547.5 \mathrm{cM}$ with an average distance of $14.25 \mathrm{cM}$ between markers. Of the 152 pairs
\end{abstract}


of microsatellite markers available for Capsicum annuum, 62 were successfully transferred to C. baccatum, generating polymorphism. Forty-two of these markers were mapped, allowing the introduction of $C$. baccatum in synteny studies with other species of the genus Capsicum.

Key words: Hot pepper; Linkage map; Segregation analyses; Molecular markers; Transferability of microsatellites

\section{INTRODUCTION}

Peppers of the genus Capsicum belong to the family Solanaceae, and are widely cultivated throughout the world (Wahyuni et al., 2013). They are considered to be one of the first spices used by mankind and they have been found along with other fossils of food dating back 6000 years (Perry et al., 2007; Hill et al., 2013). Apart from its use as a spice, the fruit and seeds of peppers are increasingly being recognized for their medicinal and antioxidant properties (Spiller et al., 2008; Dias et al., 2013; Taveira et al., 2014).

The genus Capsicum is native to South and Central America and it includes five domesticated species: Capsicum annuum, Capsicum chinense, Capsicum frutescens, Capsicum baccatum, and Capsicum pubescens (Pickersgill, 1991). Despite the economic and cultural importance of these species and their potential use in diverse markets, research concerning genetic resources and improvement of Capsicum has been developed primarily on C. annuum (Rodrigues et al., 2012).

The development of genetic maps, where wide coverage and complete analysis of the genome occurs, is considered to be one of the highest impact applications of molecular markers. Linkage maps represent a fundamental resource for the study of complex genetic traits in plant species (Chutimanitsakun et al., 2011), enabling the localization of regions that control them and the quantification of their effects on the expression of the phenotype. The first linkage map of Capsicum containing 85 random amplified polymorphic DNA (RAPD) markers was developed by Tanksley et al. (1988) using C. annuum cv. Doux des Landes crossed with $C$. chinense PI 159234. Since then, several genetic maps have been established for $C$. annuum (Lefebvre et al., 1995, 2002; Paran et al., 2004; Minamiyama et al., 2006; Barchi et al., 2007; Mimura et al., 2012; Sugita et al., 2005, 2013).

Several types of molecular markers have already been used for the development of high resolution linkage maps for $C$. annuum, including simple sequence repeats (SSRs) (Wu et al., 2009; Mimura et al., 2012; Sugita et al., 2013), RAPD (Paran et al., 2004; Barchi et al., 2007; Lee et al., 2009), restriction fragment length polymorphism (RFLP) (Sugita et al., 2005; Barchi et al., 2007; Lee et al., 2009), amplified fragment length polymorphism (AFLP) (Sugita et al., 2005; Barchi et al., 2007), and cleaved amplified polymorphic sequences (CAPS) (Lee et al., 2009). RFLPs and RAPDs are the most commonly used markers for the construction of these maps (Mimura et al., 2012). However, microsatellite markers are considered useful and the most reliable for the construction of genetic maps and QTL mapping in Capsicum populations (Sugita et al., 2013).

Lefebvre et al. (1995) developed the first integrated map for $C$. annuum using RAPD and RFLP markers, yielding a total of 85 markers arranged in 14 linkage groups and covering approximately $820 \mathrm{cM}$. Paran et al. (2004) constructed a fairly saturated map for C. annuиm resulting from the integration of six genetic maps, consisting of 2262 markers (1528 AFLPs, 440 RFLPs, 288 RAPDs, and 6 TAGs). The markers were ordered in 13 linkage groups with a total 
length of $1832 \mathrm{cM}$. Sugita et al. (2005) proposed a linkage map for pepper (C. annuum) in which 464 molecular markers were mapped (328 AFLPs, 122 RAPDs, 3 RFLPs, 7 SCARs, and 4 CAPS) in 11 major and 5 minor linkage groups, covering $1043 \mathrm{cM}$. Another map was produced by Minamiyama et al. (2006) using 106 SSR markers to map a progeny composed of $117 \mathrm{~F}_{2}$ individuals of $C$. annuum. The map consisted of 13 linkage groups and was $1042 \mathrm{cM}$ in length. Mimura et al. (2012) also developed a linkage map for the species C. annuиm based on 253 markers (151 SSRs, 90 AFLPs, 10 CAPS, and 2 TAGs covering $1336 \mathrm{cM}$ of the genome. This was the first map based on SSR markers and consisted of 12 linkage groups. However, Sugita et al. (2013) developed a map with greater coverage of the $C$. annuum genome based on 265 SSR markers, which were distributed in 12 linkage groups covering a total genetic distance of $2028 \mathrm{cM}$.

A few mapping studies have been conducted with the other cultivated species of Capsicum, which result from interspecific crossings within the $C$. annuum complex according to the compatibility and fertility of the hybrid progeny. Interspecific linkage maps originating from the crossing of C. annuum x C. frutescens (Wu et al., 2009), and of C. annuum x C. Chinense (Tanksley et al., 1988; Kang et al., 2001; Lee et al., 2009, 2011), have been constructed. For $C$. baccatum only one genetic map has been constructed based on populations derived from interspecific crosses between C. baccatum and C. annuum (Eggink et al., 2014). Nevertheless, genetic maps considering only the $C$. baccatum genetic background are no longer available in the current literature.

In this study, we construct a reference genetic map for $C$. baccatum, based on SSR, inter-SSR (ISSR), and RAPD molecular markers. Furthermore, we examine the transfer of microsatellite markers available for C. annuum to C. baccatum.

\section{MATERIAL AND METHODS}

\section{Plant material and DNA extraction}

The mapping population consisted of $203 \mathrm{~F}_{2}$ individuals originating from the crossing of UENF 1616 (female parent) and UENF 1732 (male parent). The female parent produces pungent fruit of an orange color in the intermediate stage and of a red color in the mature stage and is susceptible to pepper yellow mosaic virus (PepYMV). The male parent is characterized as very pungent, with green colored fruit in the intermediate stage and red colored fruit in the mature stage, with a slightly pronounced aroma and is resistant to PepYMV (Bento et al., 2009).

Young leaves of the two parents, and of the $F_{1}$ and $F_{2}$ generations were collected for DNA extraction according to the protocol by Doyle and Doyle (1990). The quantity of DNA was determined using a spectrophotometer (NanoDrop ND-1000, Thermo Scientific) and DNA quality was evaluated on a $1 \%$ agarose gel.

\section{Molecular markers}

\section{ISSRs and RAPD}

The ISSR primers used were proposed for pepper by Kumar et al. (2001), Refaat and Hoda (2007), and Yao et al. (2008). The evaluated RAPD primers were from the respective OPAA, OPAB, OPAC, OPB, OPE, OPF, OPK, OPN, and OPW kits from Operon Technologies (Alameda, CA, USA). In order to detect polymorphisms between the parents, 61 ISSR and 19 RAPD primers (Table 1) were used. 
M.M. Moulin et al.

6686

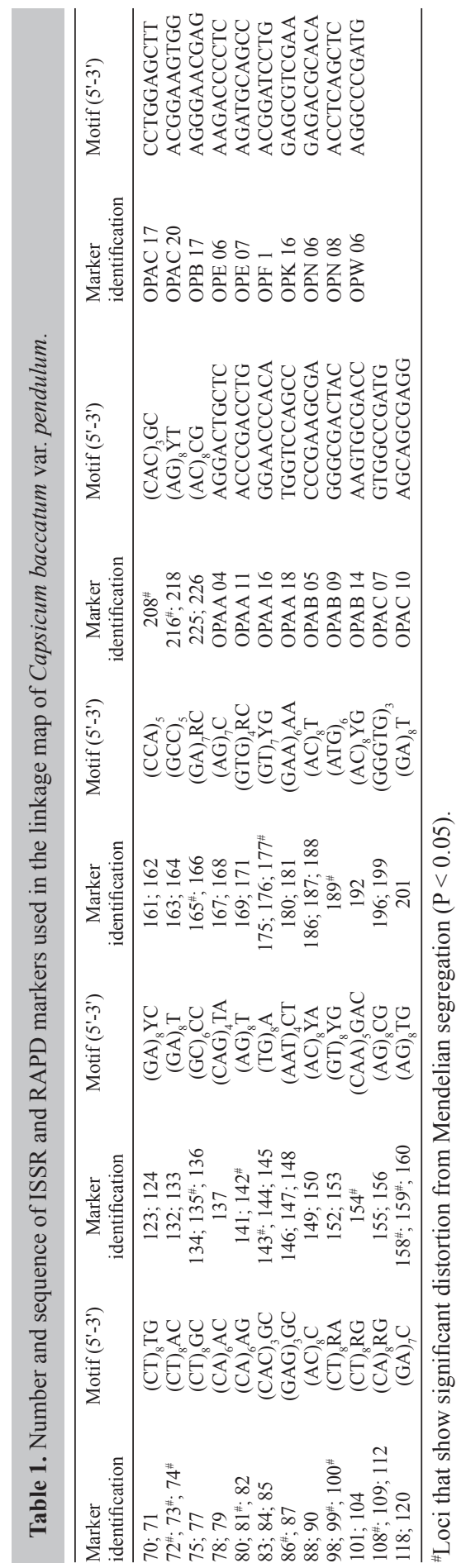


Similar amplification reactions were conducted for both ISSR and RAPD markers. The final reaction volume was $21 \mu \mathrm{L}$ and contained the following reagents: $5 \mathrm{ng}$ genomic DNA, $0.75 \mu \mathrm{L}$ Taq DNA polymerase, $10 \mathrm{X}$ buffer $(500 \mathrm{mM} \mathrm{KCl}, 100 \mathrm{mM}$ Tris-HCl, $\mathrm{pH} 8.3)$, $2.4 \mathrm{mM} \mathrm{MgCl}, 0.1 \mathrm{mM}$ of each dNTP, and $1.0 \mu \mathrm{M}$ of each primer. Two microliters of DNA was added and then $11 \mu \mathrm{L}$ of the previously described master mix was added, being added for coloring $8 \mu \mathrm{L}$ red/blue juice gel.

The PCR profile consisted of an initial denaturation step of $1 \mathrm{~min}$ at $94^{\circ} \mathrm{C}$, followed by 40 cycles of $94^{\circ} \mathrm{C}$ for $1 \mathrm{~min}$, primer annealing temperature for $1 \mathrm{~min}\left(40\right.$ to $55^{\circ} \mathrm{C}$ for ISSR primers and $37^{\circ} \mathrm{C}$ for RAPD primers), $72^{\circ} \mathrm{C}$ for $3 \mathrm{~min}$, and a final extension at $72^{\circ} \mathrm{C}$ for $7 \mathrm{~min}$. Amplification conditions were optimized for each ISSR primer to detect the most suitable temperature for the amplification. The PCR products were visualized on a $\%$ agarose gel stained with red/blue juice gel (1:1) and photographed under UV light for visualization (MiniBIS Pro, DNR Bio-Imaging Systems).

\section{SSRS}

Microsatellite markers were selected based on Minamiyama et al. (2006) for the mapping of $C$. annuum. One hundred and fifty-two pairs of microsatellite primers were tested. For the detection of polymorphism, six genotypes were chosen for testing $\left(\mathrm{P}_{1}, \mathrm{P}_{2}, \mathrm{~F}_{1}\right.$, and the three $\mathrm{F}_{2}$ individuals).

Amplification reactions were conducted in a final volume of $21 \mu \mathrm{L}$ containing the following reagents: $5 \mathrm{ng}$ genomic DNA, $0.75 \mu \mathrm{L}$ Taq DNA polymerase, $10 \mathrm{X}$ buffer $(500 \mathrm{mM}$ $\mathrm{KCl}, 100 \mathrm{mM}$ Tris-HCl, $\mathrm{pH}$ 8.3, Invitrogen), $2.4 \mathrm{mM} \mathrm{MgCl}, 0.1 \mathrm{mM}$ of each dNTP, and 0.5 $\mu \mathrm{M}$ of each primer. Two microliters of DNA was added and then $11 \mu \mathrm{L}$ of the mix previously described was added, being added for coloring $8 \mu \mathrm{L}$ red/blue juice gel.

The amplification reactions (Veriti Thermocycler, Applied Biosystems) were conducted as follows: $3 \mathrm{~min}$ at $94^{\circ} \mathrm{C}$ for initial denaturation, followed by 35 cycles of $94^{\circ} \mathrm{C}$ for $1 \mathrm{~min}, 55^{\circ}-63^{\circ} \mathrm{C}$ for $1 \mathrm{~min}$ (depending on the primer used), $72^{\circ} \mathrm{C}$ for $3 \mathrm{~min}$, and a final extension at $72^{\circ} \mathrm{C}$ for $7 \mathrm{~min}$. For preview, $8 \mu \mathrm{L}$ red/blue juice gel was added at 1:1 ratio. The amplified fragments were then separated on a high resolution MetaPhor agarose gel (4\%) and subjected to UV light for visualization (MiniBIS Pro, DNR Bio-Imaging Systems). Images of the gels were captured for subsequent analysis.

\section{Segregation analysis and map construction}

JoinMap (version 4.0) was used to construct the integrated linkage map using the methodology of van Ooijen (2006). Linkage groups were formed and sorted using a minimum LOD score of 3.0 and a maximum of $40 \%$ recombination. Linkage groups were determined using the Kosambi (1943) function for the translation of recombinatorial units to genetic distance. Markers within the resulting linkage groups were ordered relative to each other by automatic multipoint analyses using the default values of JoinMap (mapping threshold LOD $>1$, recombination frequency threshold $<0.4)$. The chi-square test $\left(\chi^{2} ; \mathrm{P}<0.05\right.$, d.f. $\left.=1\right)$ was used to test the hypotheses of 1:2:1 Mendelian segregation for SSR markers and 3:1 for ISSR and RAPD markers. 


\section{RESULTS AND DISCUSSION}

The linkage map consisted of 183 markers: 42 microsatellites (22.95\%), 85 ISSRs (46.45\%), and 56 RAPDs (30.60\%). The generated map spanned $2547.5 \mathrm{cM}$ across 12 major linkage groups (321.8 to $110.3 \mathrm{cM}$ ) and four minor linkage groups $(80.8$ to $54.2 \mathrm{cM})$ (Figure 1), each grouping from 5 to 23 markers, with an average of $159.2 \mathrm{cM}$ (Table 2).
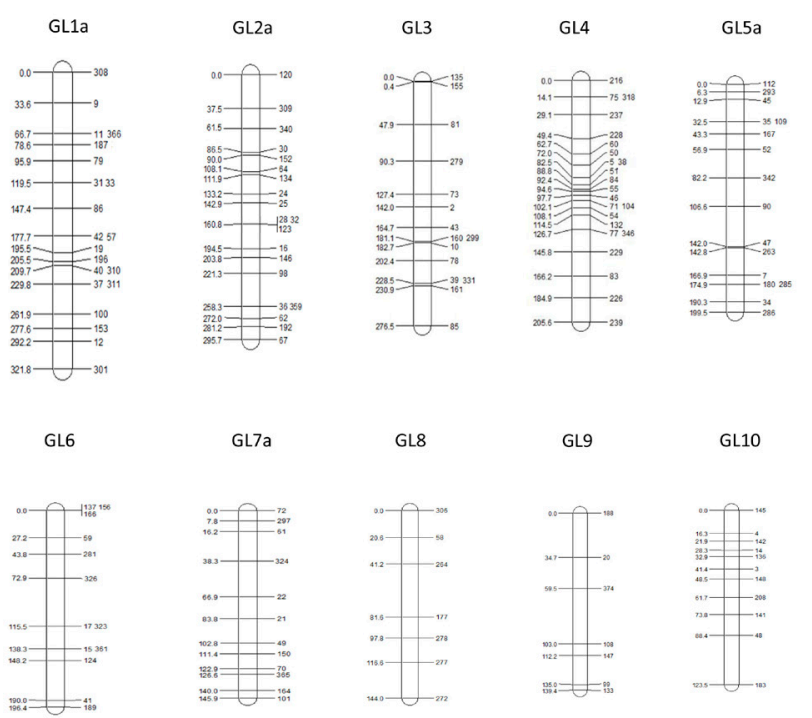

GL7a

GL8
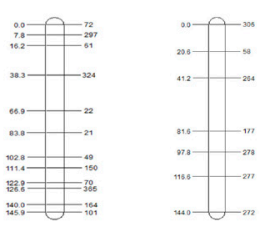

GL9

GL10

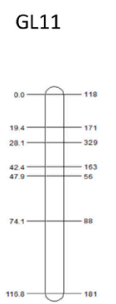

GL12

GL1b
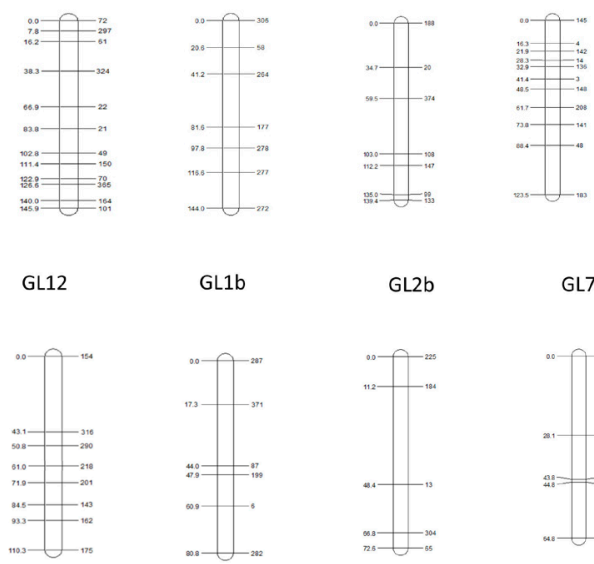

GL7b

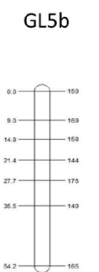

Figure 1. Genetic linkage map of Capsicum baccatum var. pendulum (LOD Score 3.0, JoinMap 4.0), showing linkage relationship of 183 molecular markers (42 SSR, 85 ISSR, and 56 RAPD) in 12 major and four minor linkage groups. The markers are indicated on the right side of each linkage group and the genetic distance $(\mathrm{cM})$ on the left side. Loci that show significant distortion from Mendelian segregation are indicated by ${ }^{\#}(\mathrm{P}<0.05)$. 
Table 2. Number, type of marker, linkage group length (cM), and mean distance between markers (cM) in the Capsicum baccatum var. pendulum linkage map.

\begin{tabular}{|c|c|c|c|}
\hline Linkage group & Number and type of markers & Size $(\mathrm{cM})$ & Average distance between markers (cM) \\
\hline GL1a & 21 (10 RAPD; 6 ISSR; 5 SSR) & 321.8 & 15.32 \\
\hline GL1b & 6 (1 RAPD; 2 ISSR; 3 SSR) & 80.8 & 13.47 \\
\hline GL2a & 20 (10 RAPD; 7 ISSR; 3 SSR) & 295.7 & 14.78 \\
\hline GL2b & 5 (2 RAPD; 2 ISSR; 1 SSR) & 72.6 & 14.52 \\
\hline GL3 & 15 (4 RAPD; 8 ISSR; 3 SSR) & 276.5 & 18.43 \\
\hline GL4 & 23 (8 RAPD; 9 ISSR; 6 SSR) & 205.6 & 8.94 \\
\hline GL5a & 16 (6 RAPD; 5 ISSR; 5 SSR) & 199.5 & 12.47 \\
\hline GL5b & 7 (ISSR) & 54.2 & 7.74 \\
\hline GL6 & 13 (4 RAPD; 5 ISSR; 4 SSR) & 196.4 & 15.11 \\
\hline GL7a & 12 (4 RAPD; 5 ISSR; 3 SSR) & 145.9 & 12.16 \\
\hline GL7b & 5 (ISSR) & 64.8 & 12.96 \\
\hline GL8 & 7 (1 RAPD; 1 ISSR; 5 SSR) & 144.0 & 20.57 \\
\hline GL9 & 7 (1 RAPD; 5 ISSR; 1 SSR) & 139.4 & 19.91 \\
\hline GL10 & 11 (4 RAPD; 7 ISSR) & 123.5 & 11.23 \\
\hline GL11 & 7 (1 RAPD; 5 ISSR; 1 SSR) & 116.8 & 16.68 \\
\hline GL12 & 8 (6 ISSR; 2 SSR) & 110.3 & 13.79 \\
\hline Mapped markers & 183 & 2547.5 & 14.25 \\
\hline Unmapped markers & 191 & & \\
\hline Total & 374 & & \\
\hline
\end{tabular}

The distance between the markers in the linkage groups ranged from 0 (i.e., two markers that co-segregate are completely linked) to $43.5 \mathrm{cM}$, with an average distance of $14.25 \mathrm{cM}$ between markers. Smaller distances than those found in the present study have previously been reported, indicating that the map developed here has a higher saturation level than previous maps and may enable better detection of QTL.

Tanksley et al. (1988) developed a reference genetic map for C. annuum using approximately 85 RAPD markers obtained from a population composed of 61 individuals (Table 3 ). As for the other species of the family Solanaceae, the first genetic map described for tomato was developed by Bernatzky and Tanksley (1986), in which 112 isozyme markers were used to map a population comprising 46 individuals, covering $760 \mathrm{cM}$ of the genome. Gebhardt et al. (1989) constructed a reference map for Solanum tuberosum using 141 RFLP markers, which covered $690 \mathrm{cM}$ of the genome, and used a population composed of only 38 individuals. A reference map created for Solanum melongena originated from a population of 168 individuals using 181 RAPD and AFLP markers to map $779.2 \mathrm{cM}$ of the genome (Nunome et al., 2001). In similar research, Priyamdha et al. (2012) reported the first genetic map for Brassica carinata, which was created by mapping an $\mathrm{F}_{2}$ population consisting of 150 individuals using 69 markers (23 RAPDs, 29 ISSRs, and 17 SSRs), using a LOD score of 3.0, and covering of $2166 \mathrm{cM}$ of the genome. The same types of markers were used by these authors and in the current study; however, the number of markers mapped for $C$. baccatum here was higher, indicating a higher saturation level for the constructed map. In addition, a larger population (203 individuals) was used, giving greater reliability to the data.

Kole et al. (2012) constructed the first genetic map for bitter melon (Momordica charantia) by mapping an $\mathrm{F}_{2}$ population consisting of 146 individuals, solely based on 108 AFLP markers, covering $3060.7 \mathrm{cM}$ of the genome. Lanteri et al. (2006) developed a reference genetic map for artichoke (Cynara cardunculus) in which a population consisting of $94 \mathrm{~F}_{1}$ individuals was used, based on 59 different primers (SSRs, AFLPs, and SSAPs), and covering $2569.9 \mathrm{cM}$ of the genome.

In the current study, an average of 2.61 useful markers were obtained using the domi- 
nant primers (ISSR and RAPD), and one useful marker was obtained using the microsatellite primers, since they enable the mapping of only one locus for an $\mathrm{F}_{2}$ population of diploid species.

\begin{tabular}{|c|c|c|c|c|c|}
\hline Species & Reference & $\begin{array}{l}\text { Population } \\
\text { size }\end{array}$ & $\begin{array}{l}\text { Number } \\
\text { of markers }\end{array}$ & $\begin{array}{c}\text { Map } \\
\text { length }(\mathrm{cM})\end{array}$ & Marker type \\
\hline Solanum lycopersicum $\mathrm{x}$ S. pennellii & Bernatzky and Tanksley (1986) & 46 & 112 & 760 & Isozymes \\
\hline Capsicum annuum $\mathrm{x} C$. chinense & Tanksley et al. (1988) & 46 & 85 & - & RAPD \\
\hline Solanum tuberosum & Gebhardt et al. (1989) & 38 & 141 & 690 & RFLP \\
\hline Capsicum annuит & Lefebvre et al. (1995) & 61 & 85 & 820 & RAPD and RFLP \\
\hline Solanum melongena & Nunome et al. (2001) & 168 & 181 & 779.2 & RAPD and AFLP \\
\hline Cynara cardunculus & Lanteri et al. (2006) & 94 & 59 & 2569.9 & SSR, AFLP and SSAP \\
\hline Brassica carinata & Priyamedha et al. (2012) & 150 & 69 & 2166 & RAPD, ISSR and SSR \\
\hline Momordica charantia & Kole et al. (2012) & 146 & 108 & 3060.7 & AFLP \\
\hline Capsicum baccatum & This study & 203 & 183 & 2547.5 & RAPD, ISSR and SSR \\
\hline
\end{tabular}

The size of the Capsicum genome is estimated to be between 3300 and $3600 \mathrm{cM}$ (Moscone et al., 2003). The linkage map constructed in this study covered between 70.76 and $77.2 \%$ of the C. baccatum var. pendulum genome, which is greater than the coverage previously obtained for $C$. annuит. Lefebvre et al. (1995) developed the first integrated map for $C$. annuиm based on 85 RAPD markers arranged in 14 linkage groups, covering approximately $820 \mathrm{cM}$ of the genome, equivalent to 22.78 to $24.85 \%$ coverage. Subsequently, other studies were undertaken to map C. annuum in order to saturate the map (Lefebvre et al., 2002; Paran et al., 2004; Sugita et al., 2005; Minamiyama et al., 2006; Barchi et al., 2007; Mimura et al., 2012).

Kang et al. (2001) published a genetic map created using a population obtained by interspecific crossing of $C$. annuит $\mathrm{x} C$. chinense, covering $1320 \mathrm{cM}$ of the genome, equivalent to 36.7 to $40 \%$ coverage. Barchi et al. (2007) developed a map for $C$. annuum with a total length of $1857 \mathrm{cM}$, representing between 51.58 and $56.27 \%$ of the genome. In the most recently published linkage map for the species (Sugita et al., 2013), which was based on 265 SSR markers distributed within 12 linkage groups, a higher total genetic distance was covered, corresponding to $2028 \mathrm{cM}$, i.e., from 56.33 to $61.45 \%$ of the genome.

When constructing the map developed in this study, the first markers to be mapped were those that followed the segregation ratio of 1:2:1 for microsatellite markers and of 3:1 for ISSR and RAPD markers. Of the mapped ISSR markers, $22.35 \%$ were distorted $(\mathrm{P}>0.05)$, whereas $14.28 \%$ of the mapped RAPD markers were distorted. For the final map, a total of 27 markers $(14.75 \%)$ were distorted (Table 4). Deviations from the expected segregation can be attributed to a number of factors, such as structural rearrangements of chromosomes, deleterious recessive alleles, gametic selection, pre- or post-zygotic selection of allelic combinations, among others (Priyamedha et al., 2012).

Using the ISSR technique and the 61 primers tested, 26 primers did not detect polymorphisms in the progeny and 35 primers showed clear polymorphism in the population studied. A total number of 85 markers were obtained and the average number of markers mapped per primer was 2.43. Among the 35 primers used, a total of 201 loci were amplified, from which 85 were mapped. For the RAPD markers, 24 primers were tested, of which five did not detect polymorphism, and 19 were selected. A total of 56 markers were generated, with an average of 2.95 mapped markers per primer. For the 19 RAPD primers, a total of 111 loci were produced, of which 56 were polymorphic for the parents and were mapped. 
From the 152 microsatellite markers available for $C$. annuum and tested in C. baccatum var. pendulum, 62 were successfully transferred and considered polymorphic and 42 were mapped, resulting in $40.8 \%$ of microsatellite markers being transferred. As information about the transferability and use of microsatellites for C. baccatum is limited, the construction of linkage groups incorporating these markers of a co-dominant nature represents a valuable strategy for genomic studies on the species.

Table 4. Molecular markers selected to construct the reference linkage map of Capsicum baccatum var.
pendulum.

There was good correspondence between the allocation of microsatellite markers in the linkage groups of C. baccatum var. pendulum obtained in this study and those from the linkage group of $C$. annuum obtained by Minamiyama et al. (2006). Of the microsatellite markers mapped here, $66.67 \%$ were common to the linkage groups constructed by Minamiyama et al. (2006). This high similarity is of great relevance to studies on synteny and comparative mapping with other species of Capsicum.

In the map developed here, 191 loci were not mapped, suggesting that over half $(51.07 \%)$ of the markers were not linked. These unallocated markers show that the saturation level of the obtained map needs to be increased. These available, unlinked markers facilitate the saturation of the map with the addition of new markers obtained in further studies. Mimura et al. (2012) found that as the coverage of a genetic map increases, the number of linkage groups becomes closer to the haploid number of chromosomes of the species and the number of unlinked markers approaches zero. Barchi et al. (2007) observed that approximately $50 \%$ of the markers of $C$. annuum were considered unlinked in a test at the $1 \%$ level performed using the 304 Mapmaker software. Studies conducted by Lee et al. (2011) obtained better results than those obtained in this study, with only $31.5 \%$ of the markers not mapped compared to $51.07 \%$ in the current study. However, these authors worked with an interspecific crossing $(C$. annuum $\mathrm{x} C$. chinense), which extends the generated polymorphism, as well as the number of linkage groups, allowing the allocation of most of the markers.

Subdivision of the linkage groups 1,2,5, and 7 was carried out, because although they contained gaps determined by mapped markers they were over $50 \mathrm{cM}$. To this end, we added a letter to the number of the original linkage group. Groups $1 b, 2 b, 5 b$, and $7 b$ resulted from this subdivision, allowing 6,5,7, and 5 markers, respectively, to be maintained in the linkage groups. The subdivision indicates that the markers are within the same group; however, there are not enough markers to group them. According to Priyamedha et al. (2012), the existence of gaps in linkage groups is expected for species with a larger genome, even if a high number of maps have already been developed.

In maps constructed for Capsicum with different types of markers and different types of mapping populations, the presence of gaps is quite common due to the size of the genome. Kang et al. (2001) constructed a genetic map with 11 major linkage groups (60.3-206 cM), 
and five minor linkage groups $(10.3-32.6 \mathrm{cM})$. Similar results were obtained by Sugita et al. (2005), where the genetic map also consisted of 11 major linkage groups $(56.7-118.5 \mathrm{cM})$, and five minor linkage groups $(1.8-33.1 \mathrm{cM})$.

According to Paran et al. (2004), it is possible to obtain a number of linkage groups that differs from the haploid number of the species, indicating that a higher saturation is needed to achieve complete coverage of the pepper genome. Conversely, all markers found with a distance smaller than $50 \mathrm{cM}$ should be retained as these are fundamental to the higher saturation of the map with the introduction of new markers.

With regards to the number of linkage groups, genetic maps developed by Mimura et al. (2012) and by Sugita et al. (2013) showed 12 groups, equivalent to the haploid number of the species, C. annuum, while Alimi et al. (2013) constructed a map for the same species with 17 linkage groups.

In the current study, a higher concentration of certain types of markers was found in certain linkage groups. The clustering of markers in specific areas of the genome is a common phenomenon in the development of genetic maps and it has been previously described in several species and for different types of markers (Qi et al., 2004). In order to explain this concentration, biological factors, such as the low rate of recombination in regions of centromeres and telomeres, the discontinuous distribution of levels of polymorphism and the variation in the number of copies of certain sequences throughout the genome, have been highlighted (Tanksley et al., 1992; Qi et al., 2004).

The map constructed in this study enables the inclusion of $C$. baccatum in genomic studies, such as comparative mapping, and it can be used as a starting point for selecting features of interest for plant improvement. Furthermore, the identification of polymorphic microsatellite markers represents a major breakthrough for the implementation of marker-assisted selection in programs for the improvement of $C$. baccatum, and it also allows the culture to benefit from advances in genetics and genomics of other most studied species, such as $C$. annuum. From this reference map, the inclusion of new markers can be made, enabling major, and improved, coverage of the genome, and also a better definition of the linkage groups.

\section{ACKNOWLEDGMENTS}

Research supported by the Brazilian agencies Fundação Carlos Chagas Filho de Amparo à Pesquisa do Estado do Rio de Janeiro (FAPERJ) and Conselho Nacional de Desenvolvimento Científico e Tecnológico (CNPq) for grants FAPERJ (Proc. \#E-26/103.156/2011 and \#E-26/110.746/2012) and CNPq (Proc. \#305929/2013-5).

\section{REFERENCES}

Alimi NA, Bink MCAM, Dieleman JA, Nicolar M, et al. (2013). Genetic and QTL analyses of yield and a set of physiological traits in pepper. Euphytica 190: 181-201.

Barchi L, Bonnet C, Boudet C, Signoret P, et al. (2007). A high-resolution, intraspecific linkage map of pepper (Capsicum annиит L.) and selection of reduced recombinant inbred line subsets for fast mapping. Genome 50: 51-60.

Bento CS, Rodrigues R, Zerbini Júnior FM and Sudré CP (2009). Sources of resistance against the Pepper yellow mosaic virus in chili pepper. Hortic. Bras. 27: 196-201.

Bernatzky RB and Tanksley SD (1986). Toward a saturated linkage map in tomato based on isozymes and random cDNA sequences. Genetics 112: 887-898.

Chutimanitsakun Y, Nipper RW, Cuesta-Marcos A, Cistué L, et al. (2011). Construction and application for QTL analysis 
of a Restriction Site Associated DNA (RAD) linkage map in barley. BMC Genomics 12: 4-12.

Dias GB, Gomes VM, Moraes TM, Zottich UP, et al. (2013). Characterization of Capsicum species using anatomical and molecular data. Genet. Mol. Res. 12: 6488-6501.

Doyle JJ and Doyle JL (1990). Isolation of plant DNA from fresh tissue. Focus 12: 13-15.

Eggink PM, Tikunov Y, Maliepaard C, Haanstra JPW, et al. (2014). Capturing flavors from Capsicum baccatum by introgression in sweet pepper. Theor. Appl. Genet. 127: 373-390.

Gebhardt C, Ritter T, Debener U, Schachtschabel B, et al. (1989). RFLP analysis and linkage mapping of Solanum tuberosum. Theor. Appl. Genet. 78: 65-75.

Hill TA, Ashrafi H, Reyes-Chin-Wo S, Yao J, et al. (2013). Characterization of Capsicum annuum genetic diversity and population structure based on parallel polymorphism discovery with a $30 \mathrm{~K}$ unigene pepper GeneChip. PLoS One 8: e56200.

Kang BC, Nahm SH, Huh JH, Yoo HS, et al. (2001). An interspecific (Capsicum annuum $x$ C. chinense) $\mathrm{F}_{2}$ linkage map in pepper using RFLP and AFLP markers. Theor. Appl. Genet. 102: 531-539.

Kole C, Olukolu BA, Kole P, Rao VK, et al. (2012). The first genetic map and positions of major fruit trait loci of bitter melon (Momordica charantia). J. Plant Sci. Mol. Breed. 1: 1-6.

Kosambi DD (1943). The estimation of map distance from recombination values. Ann. Eugen. 12: 172-175.

Kumar LD, Kathirvel M, Raoand GV and Nagaraju J (2001). DNA profiling of disputed chilli samples (Capsicum annuum) using ISSR-PCR and FISSR-PCR marker assays. Forensic Sci. Int. 116: 63-68.

Lanteri S, Acquadro A, Comino C, Mauro R, et al. (2006). A first linkage map of globe artichoke (Cynara cardunculus var. scolymus L.) based on AFLP, S-SAP, M-AFLP and microsatellite markers. Theor. Appl. Genet. 112: 1532-1542.

Lee HR, Bae IH, Park SW, Kim HJ, et al. (2009). Construction of an integrated pepper map using RFLP, SSR, CAPS, AFLP, WRKY, rRAMP, and BAC end sequences. Mol. Cells. 27: 21-37.

Lee HR, Kim KT, Kim HJ, Han JH, et al. (2011). QTL analysis of fruit length using rRAMP, WRKY, and AFLP markers in chili pepper. Hort. Environ. Biotechnol. 52: 602-613.

Lefebvre V, Palloix A, Caranta C and Pochard E (1995). Construction of an intraspecific integrated linkage map of pepper using molecular markers and doubled-haploid progenies. Genome 38: 112-121.

Lefebvre V, Pflieger S, Thabuis A, Caranta C, et al. (2002). Towards the saturation of the pepper linkage map by alignment of three intraspecific maps including known-function genes. Genome 45: 839-854.

Mimura Y, Inoue T, Minamiyama Y and Kubo N (2012). An SSR-based genetic map of pepper (Capsicum annuum L.) serves as an anchor for the alignment of major pepper maps. Breeding Sci. 62: 93-98.

Minamiyama Y, Tsuro M and Hirai M (2006). An SSR-based linkage map of Capsicum annuum. Mol. Breed. 18: 157-169.

Moscone EA, Baranyi M, Ebert I, Greilhuber J, et al. (2003). Analysis of nuclear DNA content in Capsicum (Solanaceae) by flow cytometry and Feulgen densitometry. Ann. Bot. 92: 21-29.

Nunome T, Ishiguro K, Yoshida T and Hirai M (2001). Mapping of fruit shape and color development trait in eggplant (Solanum melongena L.) based on RAPD and AFLP markers. Breeding Sci. 51: 19-26.

Paran I, van der Voort JR, Lefebvre V, Jahn M, et al. (2004). An integrated genetic linkage map of pepper (Capsicum spp.). Mol. Breed. 13: 251-261.

Perry L, Dickau R, Zarrillo S, Holst I, et al. (2007). Starch fossils and the domestication and dispersal of chili peppers (Capsicum spp. L.) in the Americas. Science 315: 986-988.

Pickersgill B (1991). Cytogenetics and evolution of Capsicum L. In: Chromosome engineering in plants: genetics, breeding, evolution. Part B (Tsuchiya T and Gupta PK, eds.). Elsevier Science Publishers, Amsterdam, 139-160.

Priyamedha, Singh BK, Kaur G, Sangha MK, et al. (2012). RAPD, ISSR and SSR based integrated linkage map from an $\mathrm{F}_{2}$ hybrid population of resynthesized and natural Brassica carinata. Natl. Acad. Sci. Lett. 35: 303-308.

Qi X, Pittaway TS, Lindup S, Liu H, et al. (2004). An integrated genetic map and a new set of simple sequence repeat markers for pearl millet, Pennisetum glaucum. Theor. Appl. Genet. 109: 1485-1493.

Refaat MH and Hoda ASE (2007). Relationship between hybrid performance and genetic diversity based on ISSR-PCR markers in Pepper (Capsicum annuum L.). Ann. Agri. Sci. 45: 1565-1579.

Rodrigues R, Gonçalves LSA, Bento CS, Sudré CP, et al. (2012). Combining ability and heterosis for agronomic traits in chili pepper. Hort. Bras. 30: 226-233.

Spiller F, Alves MK, Vieira, SM, Carvalho TA, et al. (2008). Anti-inflammatory effects of red pepper (Capsicum baccatum) on carrageenan- and antigen-induced inflammation. J. Pharm. Pharmacol. 60: 473-478.

Sugita T, Kinoshita T, Kawano T, Yuji K, et al. (2005). Rapid construction of a linkage map using high-efficiency genome scanning/AFLP and RAPD, based on an intraspecific, doubled-haploid population of Capsicum annuum. Breeding Sci. 55: 287-295.

Sugita T, Semi Y, Sawada H, Utoyama Y, et al. (2013). Development of simple sequence repeat markers and construction of a high-density linkage map of Capsicum annuum. Mol. Breed. 31: 909-920. 
Tanksley SD, Bernatzky R, Lapitan NL and Prince JP (1988). Conservation of gene repertoire but not gene order in pepper and tomato. Proc. Natl. Acad. Sci. U. S. A. 85: 6419-6423.

Tanksley SD, Ganal MW, Prince JP, de-Vicente MC, et al. (1992). High density molecular linkage maps of the tomato and potato genomes. Genetics. 132: 1141-1160.

Taveira GB, Mathias LS, da Motta OV, Machado OLT, et al. (2014). Thionin-like peptides from Capsicum annuum fruits with high activity against human pathogenic bacteria and yeasts. Biopolymers 102: 30-39.

van Ooijen JW (2006). JoinMap 4.0. Software for the calculation of genetic linkage maps. Kyazma BV, Wageningen, 63.

Wahyuni Y, Ballester AR, Tikunov Y, de Vos RC, et al. (2013). Metabolomics and molecular marker analysis to explore pepper (Capsicum sp.) biodiversity. Metabolomics 9: 130-144.

Wu F, Eannetta NT, Xu Y, Durrett R, et al. (2009). A COSII genetic map of the pepper genome provides a detailed picture of synteny with tomato and new insights into recent chromosome evolution in the genus Capsicum. Theor. Appl. Genet. 118: 1279-1293.

Yao H, Zhao Y, Chen DF, Chen JK, et al. (2008). ISSR primer screening and preliminary evaluation of genetic diversity in wild populations of Glycyrrhiza uralensis. Biol. Plantarum. 52: 117-120. 